University of Nebraska - Lincoln

DigitalCommons@University of Nebraska - Lincoln

To Improve the Academy

Professional and Organizational Development Network in Higher Education

1997

\title{
Teaching Improvement Consultation for Teaching on Television
}

Joyce Povlacs Lunde

Myra S. Wilhite

University of Nebraska-Lincoln, mwilhite1@unl.edu

Follow this and additional works at: https://digitalcommons.unl.edu/podimproveacad

Part of the Higher Education Administration Commons

Povlacs Lunde, Joyce and Wilhite, Myra S., "Teaching Improvement Consultation for Teaching on Television" (1997). To Improve the Academy. 384.

https://digitalcommons.unl.edu/podimproveacad/384

This Article is brought to you for free and open access by the Professional and Organizational Development Network in Higher Education at DigitalCommons@University of Nebraska - Lincoln. It has been accepted for inclusion in To Improve the Academy by an authorized administrator of DigitalCommons@University of Nebraska - Lincoln. 
Lumde, J. P., \& Wilhite, M. S. (1997). Teaching improvement consultation for teaching on television. In D. DeZure (Ed.), To Improve the Academy, Vol. 16 (pp. 67-90). Stillwater, OK: New Forums Press and the Professional and Organizational Development Network in Higher Education. Key Words: Distance Education, Faculty Development, Television, Instructional Design.

\section{Teaching Improvement Consultation for Teaching on Television}

\section{Joyce Povlacs Lunde}

\section{Myra S. Wilhite}

University of Nebraska-Lincoln

Instructional consultants have traditionally offered individual consultation to faculty members on their campuses to improve teaching and learning. This kind of consultation to improve teaching is also valuable for those teaching on television, but consultants may need to prepare themselves in learning technologies and distance education in order to help faculty offering instruction via television. In addition, the phases of initial interview, data-gathering, data-feedback, implementation, and evaluation, which constitute a process often used to improve teaching, need to be expanded to address teaching over television.

Teaching via satellite delivery - teaching on television-is one mode of teaching students at a distance that a number of college faculty experience as their initial exposure to learning technologies (Alley, 1996; Drops, 1996; Rockwell \& King, 1995). As faculty members plan instruction using new technologies, the technology itself may seem to dominate the preparation, with the teacher's role located somewhere 
in the background. However, in live television delivery of instruction, the teacher is very much in the foreground-and the rules have changed (Alley, 1996).

Just as a teacher must make the transition between the traditional classroom and television teaching, so too does the instructional consultant whose role has been to guide the process of improving teaching in traditional classroom settings. A number of players have now entered the field, including instructional designers, graphics artists, specialists at computing resources centers, and educational television technicians, producers and directors. In this new environment, instructional consultants operating out of teaching and learning centers must prepare themselves for new kinds of individual consultation. The authors of this paper (experienced instructional consultants, one of whom has taught via television) offer suggestions to prepare the consultant for distance and multimedia technologies and propose an expanded model of the teaching improvement process for television teaching.

\section{Preparation for the Instructional Consultant}

In the earlier days of faculty development, two main approaches to providing instructional assistance were identified: instructional development (planning or revising a course) and teaching improvement (improving teaching skills while a course was in progress) (Phillips and Bergquist, 1975; Gaff, 1976; R. Diamond, 1988). Today the picture is more complex, partly as a result of a greater emphasis being placed on a team approach to preparation and delivery of distance education (Gilbert, 1995; Moore \& Kearsley, 1996). In fact, the traditional role of a faculty member may be split between that of a "content expert" who works with the design team and the "instructor" who actually delivers the class (Moore \& Kearsley, 1996). Given these many new dimensions of classroom teaching, the first step in offering teaching improvement for faculty members who teach on television may be professional development for consultants themselves.

Instructional consultants who come from a variety of disciplines across higher education may not have the expertise needed to help 
faculty improve their teaching in settings of distance delivery and technology. The instructional design team for television teaching may not even include the services of an instructional consultant who focuses on teaching improvement during the life of the course (Moore \& Kearsley, 1996). Yet "pedagogical expertise" (Gilbert, 1996) is a major type of service offered by instructional consultants. Therefore, instructional consultants should be prepared to be part of the team. Following are suggestions for instructional consultants who wish to prepare themselves to work with faculty members teaching in distance settings:

- Observe expert or experienced television instructors in person or on video, perhaps interviewing them to capture the best principles found in their approaches to distance teaching.

- Discover how faculty members are already receiving assistance in designing and offering instruction via distance. Who are the players already in place? Instructional television designers? Computer technicians who teach faculty various software programs? A television producer and director? Is there a process and a team already in place who can assist the faculty member from start to finish?

- Become familiar with campus resources available to the distance education instructor. Take time to visit units, such as academic telecommunications, university television, and instructional technology groups, to learn what is available. Begin to build links with those who offer the various services.

- Learn the basic language and vocabulary of technology, distance education, and computing. Although this task may seem overwhelming, it can be done on a learn-as-you go basis (Rogers, 1995; Saltrick, 1994).

- Learn about the basic tools of distance education, such as audiobridge telephone links ("bridge"), the documents camera, presentation packages, imported Web pages and Internet data and programs, list-servs and electronic discussion groups. While instructional consultants may not become technical experts, they should know how tools are accessed and employed in the medium of television teaching (Baer, 1994). 
- Participate in on-campus workshops and video conferences on distance education along with faculty colleagues who are interested in teaching via distance. The consultant will not only learn about the technology, but also will make contact with individual faculty members who may become clients. In addition to on-campus workshops, each semester several national video conferences may be downlinked on one's own campus, for example, recent ones sponsored by the National University Telecommunications Network (Old Dominion University), the University of Wisconsin Cooperative Extension, and the Education Network of Maine.

- Familiarize yourself with resources such as articles and questionnaires which suggest principles of effective teaching for television instruction and are useful in designing tools for feedback for instruction via distance (for example, Cyrs \& Smith, 1990; Battan; 1996; Willis, 1992; Willis, 1993). Workshops on distance education will usually have many handouts or provide manuals with recommendations about teaching on television (for example, Scott \& Aden, 1996).

- Establish new client networks by identifying who is currently engaged in teaching on television, what departments are encouraging distance delivery of their courses, and how your services might be part of the resource group for the faculty member.

- Be ready to empathize with faculty members in new ways. Keep in mind that "almost no one finds their initial experience with any new technology to be a simple and pleasant experience" (Saltrick, 1994). In the television medium, weaknesses or flaws are magnified over television delivery. Another worry is the loss of control in teaching: everything from unpredictable camera work to glitches in picture and sound can cause distuption. The consultant needs to provide extra support for the inevitable lows that the instructor will experience as well as leave time to celebrate the highs. Instructors must be encouraged to continue to take risks in this medium. Be prepared to be reassuring when technical difficulties arise. The consultant may also need to schedule extra time to listen and affirm.

- Proceed with confidence. Recognize that the professional development process is continuous and do not hesitate to jump into a 
consultation involving television teaching. After all, consultants know the principles and strategies of effective teaching and active learning; they are trained guides in the process of data-gathering, feedback, and implementation; and at the very least they can serve as a calm, reflective friend or even advocate for the person engaged in the maelstrom of live television teaching.

\section{The Teaching Improvement Process}

The Teaching Improvement Process and its variations have long been a staple of individual consultation for teaching improvement in postsecondary education (Lewis, 1988). This process, in its simplest form, consists of five phases: (1) an initial interview or meeting in which the consultant and faculty member determine the goals of the teaching improvement process; (2) data collection, involving observations and student feedback; (3) a data review or feedback session with the instructor; (4) implementation strategies for improvement selected by the instructor in consultation; and (5) evaluation of the improvement and the teaching improvement process (Povlacs, 1988). With the advent of the use of multiple technologies for teaching, the Teaching Improvement Process takes on new complexities and hence the five phases of the process need expanding and transforming, as suggested below.

\section{Schedule initial meeting(s).}

Normally, in the initial meeting which lasts about an hour, the instructor describes the course, students, and facilities, states teaching goals, and gives other relevant information. However, the complexity of the situation in teaching over television may overwhelm a single visit. The consultant needs to ask not only about subject matter, the facilities, the learners, and the teacher's goals, but also delve through the layers of variables technology has added.

In assisting a faculty member who is teaching on television, the consultant needs to determine the specific technical and logistical arrangements. Television instruction may involve two-way video and audio, with the instructor viewing the students at a number of different sites; it may mean one way video and two-way audio, when the 
instructor cannot see students at the sites, but with either an open microphone or an 800 number for students to call; or there may be some combination of these technical capabilities. Teaching on television may also involve electronic discussion groups, faxed answers to questions, and use of Websites for further instruction. The library and the computer center may be involved in getting students linked to instruction.

The consultant should not only be aware of what is available and what the faculty member expects to use, but also find out how much experience or training the teacher has in using the tools. The consultant must also ask about the others involved in the course, from co-instructors to technical personnel, and determine what control the instructor has over what is transmitted. For example, did the instructor design graphics and select background music for theme song and breaks? Some campuses have a systematic way of producing televised instruction, from initial contact to final product, while others are informal and still feeling their way along this kind of instruction. In the former case, the instructor may not have full control of what is transmitted, how and when; in the latter case, instructor control may be ambiguous. In either case, improving instruction becomes a process of negotiation involving others. However, if the instructor is teaching in a state of the art classroom designated for distance education, it is possible for the entire course to be managed and produced by the course instructor without the intervention of media professionals.

It may be more efficient and less stressful to gather some information about the particular teaching situation via telephone or e-mail. A simple questionnaire completed ahead of the initial meeting can yield information about the instructor's familiarity with the technology (see Appendix A). The instructional consultant might use a technology questionnaire, e-mail questions and answers as well as telephone interviews to elicit information before meeting face-to-face to talk about the immediate teaching situation and what the instructor wishes to achieve. In short, more than one "initial interview" utilizing various means of communication may be needed.

Once the teaching situation is determined and the level of the teacher's comfort and expertise in handling available tools have been made clearer, the consultant can focus on teaching itself. What are the 
teacher's goals for the course and for the consultation? The consultant needs to listen for both strengths and concerns. Are there unrealistic expectations about time, use of electronic tools, and site accessibility? Who are the students and where are they located? Has there been anything done to plan for live interaction? How comfortable is the instructor with teaching on television? The initial conference ends, as might be expected, with a mutually agreed upon plan and schedule for data gathering and feedback.

\section{Gather the Data.}

After the initial conference, the instructional consultant begins to gather data in the mode and format as agreed upon while the course is running. The usual data-gathering tools of observation, student feedback, and videotaping take on new dimensions in distance teaching.

- Observation. Observing the class means that the consultant sits in or has access to both the up-linking and down-linking sites. Whatever methods of note-taking during observations are used (Lewis, 1988; Acheson, 1981), the consultant needs to keep in mind that both perceptions and classroom experience differ between on-campus and off-campus sites. Can you observe students at each site, or at least listen in to other sites? Can you view what the student sees at remote sites? The instructional consultant may observe the classroom several different times to sample the variety of teaching strategies incorporated as well as experience the technical successes and disasters. A consultant's perspective will be too narrow if it is focused on a single setting and a one dimensional observation.

- Student feedback. Various means of gathering student feedback have been described in faculty development literature over the years (Lewis, 1988; Sorenson, 1994; Brinko \& Menges, 1997). The questionnaire Teaching Analysis by Students (TABS) used to gather mid-term feedback is still a useful tool, especially in a shortened version-TABS-C (Teaching and Learning Center, $\mathrm{n}$, d.). The television teacher may have someone else administer the questionnaire, but the responses should go to the consultant. On-campus responses should be kept separate from remote site 
responses in scoring. Even if the responses from different sites may not turn out to be statistically different, the instructor will have whatever information is relevant and the off-campus students will know they have a voice.

Consultants could also attempt Small Group Instructional Diagnosis (SGID) (N. Diamond, 1988), going before the television camera themselves. If enrollment is small, each site may be a separate group; if students are isolated off campus, they may still be connected by a telephone bridge. Other data gathering questionnaires may be customized to the distance education situation. Both on-campus and off-campus students are experiencing something other than traditional classroom instruction, and both groups of students need to be heard. Collecting data from remote site students may take more time, especially if the feedback comes in the form of a questionnaire to be returned by mail. In addition to feedback from students taking the course, information and perceptions could be gathered from teaching assistants and from technical persons who are involved in transmission (see Appendix B).

- Videotaping. In the past, one mode of data collection often difficult to arrange is videotaping the teacher in the classroom. Because most television courses are automatically videotaped, however, there is an abundant supply of videotape instruction for feedback. Arranging to view some portion of the videotape with the teacher may be one form of the consultation. Most likely, the teacher will be replaying the tapes after each class. In this case, the consultant may need to develop a customized guide sheet either for a videotape feedback session or for review by the instructor alone. (An example of a traditional form is found in Appendix C, Arizona Board of Regents, 1982; also see Davis, 1993, pp. 355-361. Batten, 1996, and Willis, 1992, have forms and questions suited for distance education approaches.)

\section{Conduct Data-feedback.}

In some forms of instructional consultation, data-feedback is clearly separated from data-gathering. In practice, it is useful to meet 
with the instructor as soon as possible after the session is observed and give descriptive feedback. Because television teaching involves higher visibility and greater stress, giving descriptive feedback allays anxiety and focuses dialogue on coping with the demands of the television medium. Therefore, consultants should not withhold observational feedback until all data are in, which may involve waiting for the mail and may not be ready for weeks. When the input is completed and questionnaires have been scored, the consultant should organize the information, separating on-campus and off-campus data. Arranging the feedback thematically around such topics as interaction, use of technology, or clarity, might make the feedback session less overwhelming. Given the feeling the teacher has that television exposes his or her foibles to vast audiences, it is even more important that the data be cast in a positive light and that the consultant convey the attitude that change is actually possible.

\section{Encourage Implementation.}

At the end of the feedback phase, the consultant should be able to help the instructor form generalizations and develop a plan of action to achieve both short term and longer term goals. Areas in which improvement may be made during the course include:

- Structure and clarity. The documents camera or presentation software which is transmitted from a computer are useful to present major points at the beginning of class and to mark transitions. Course manuals with assignments spelled out and outlines for each class meeting are expected, if not mandatory. If there is no course manual, it may be prepared "as you go" for each lesson. In general, redundancy is especially important in teaching via television because the instructor lacks the visible, non-verbal cues students use to signal puzzlement or confusion and verbal instructions can be lost in the uncertainties of transmission.

- Variety. The medium of television may seem at first to encourage teacher talk. If the teacher is talking too much and the image and presentation are too bland, variety can still be introduced. Materials can be presented in a colorful way-graphics, movement, music, pictures-as long as there are no copyright infringements. 
(For fair use practices, see Crews \& Okerson, 1995.) Instructors can bring to class videotaped examples or cases which may need only minimal production time. Inviting guest presenters, chosen for their enthusiasm as well as expertise, varies the face on the screen (and also gives colleagues a chance to teach on television). Finally, students should also be involved in the medium in individual presentations or group reports (Drops, 1996).

- Interaction. Handling the call-ins from the sites is one of the most difficult functions of television teaching. Merely running an $\mathbf{8 0 0}$ number on the screen for students to call-in questions, without any further prompts, is about as effective as routinely asking "Are there any questions?" in the traditional classroom. Discussion periods involving both on-campus and off-site students need to be planned, including questions to ask, time allowed for students to prepare answers (alone or in groups), call-in or report order, time for reports and mode of answering (oral report, fax, or transmission via the documents camera). Other ways of promoting student learning include using off-air class-time for student work, such as small group work or performances which can be videotaped and sent to the course instructor (Rockwell \& King, 1995).

- Interpersonal communication. If enrollment patterns allow, building communities of learners at each site is not hard to do and pays dividends in student perceptions of what they are gaining. Teaching associates who are individuals drawn from Cooperative Extension or other educational units and serve as discussion leaders at off-campus sites are one means of helping to build community. Telephone bridges can be used to connect students across sites. The teacher, teaching associates, and students should learn about the others in the class and their names as well. This process is enhanced if the teacher and guest presenters call on students by name and if students at off-campus sites send in pictures to be used when they are speaking. Using pictures of class members and the teacher superimposed over text on presentation software or the documents camera is yet another means of establishing the connection to real people.

- Improving technical quality. Feedback from the sites might focus on the quality of the picture received, poor camera work or picture 
selection, wrong pictures of discussants, or other technical problems. What is delivered via television is often the pretogative of the producer/director. In this case, the instructional consultant can help the faculty member work with those involved in the technical delivery.

- Creative uses of technology. Teaching on television can encourage interactive learning and student performance. Off-camera videotaping of group presentations may double-up on time, with best cases selected for presentation on television the next week. Students can respond on fax or e-mail if they seem too "shy" to participate in "synchronous" or live broadcasts (Chickering \& Ehrmann, 1996). If the technology is posing a problem, there is frequently a creative solution. If the satellite fails, telephone lines, fax, videotape and e-mail are available. Because instructional consultants may be operating out of a set of principles and practices which differ from those engaged in the technical side, they may see different ways of increasing students' involvement in learning.

\section{Evaluate.}

The last phase of the Teaching Improvement Process involves an evaluation of both changes the faculty member may have made and of the process itself. In television teaching, improvements and changes can be dramatic. To assess change, the instructor can view videotapes from the classes later in the semester and also gather student feedback on those items which were targeted for improvement. Students could respond by fax or e-mail to a simple questionnaire about improvements they have observed. Items selected from TABS-C might also be used to measure improvement. If the instructor is not already gathering regular feedback from students, the consultant can call the instructor's attention to classroom assessment techniques, such as "The Minute Paper" or "Muddiest Point" (Angelo \& Cross, 1993).

At the end of the consultation, the teacher and the consultant may want to compare notes on their different perspectives. A focused discussion of the differences between teaching on television and in the regular classroom might be enlightening for both. Also, the instructor 
might wish to discuss differences in students' attitudes and cognitive gains in comparisons between past and present classes. Helping faculty members to identify and document these differences may have an impact on their future teaching in both traditional and television settings.

\section{Conclusion}

Instructional consultation can be an important service for faculty engaged in distance education. Although the faculty member may have access to instructional design services and technical assistance, the instructional consultant can provide both a process to improve teaching and support while teaching on television is in-progress.

Instructional consulting for television teaching is embedded in multiple contexts. In addition to individual services, teaching and learning centers should enrich the environment for multi-media teaching by:

- sponsoring multimedia seminars and workshops;

- identifying and linking faculty members who are-or will beengaged in television teaching, and linking novices to experienced television teachers;

- conducting needs assessments and compiling important issues and concerns instructors and their students have about teaching and learning on television;

- acquiring and offering resource materials already available or developing an in-house manual or hand-outs on television teaching; and

- organizing discussion groups around technology issues.

In the future, almost all instructional consultants and their teaching and learning centers will need to expand their essential services to those teaching in new modalities. In this endeavor, expect the learning curve to be steep, sometimes treacherous, and constantly amazing for those who venture on the journey. 


\section{References}

Acheson, K. A. (1981, January). Classroom observation techniques. (Idea Paper No. 4). Manhattan, KS: Center for Faculty Evaluation and Development, Kansas State University.

Alley, L. R. (1996, March/April). An instructional epiphany. Change, 49-51.

Angelo, T. A., \& Cross, K. P. (1993). Classroom assessment techniques: A handbook for college teachers (2nd ed.). San Francisco: Jossey-Bass.

Arizona Board of Regents. (1982). Criteria for self-evaluation of teaching [videotape]. (Available from Tempe, AR: Arizona State University, Office of Instructional Design and the Unversity Program for Faculty Development).

Baer, E. R. (1994, Fall). Muddling through educational improvement: Deans and technology. The Department Chair, 4, 14-16.

Batten, C. (1996, March). Observable and measurable competencies of an ITV instructor. Connie's home page. [On-line]. Available: http://spidome.net/"bins/connie.html.

Bergquist, W.H., \& Phillips, S. R. (1975). Components of an effective faculty development program. Journal of Higher Education, 46, 177-209.

Brinko, K. T., \& Menges, R. J. (Eds.). (1997). Practically speaking: A sourcebook for Instructional consultants in higher education. Stillwater, OK: New Forums Press.

Chickering, A., \& Ehrmann, S. (1996, October). Technology and the seven principles. American Association for Higher Education Bulletin, 49, 3-4.

Crews K. D. \& Okerson A. (1995). Copyright, fair use, and the challenge for universities: Promoting the progress of higher education. College and Research Libraries, 56, 284-285.

Cyrs, T. E., \& Smith, F. A. (1990). Teleclass teaching: A resource guide (3rd ed.). Las Cruces, NM: New Mexico State University, Center for Educational Development.

Davis, B. G. (1993). Tools for teaching. San Francisco: Jossey-Bass.

Diamond, N. (1988). S.G.I.D. (Small Group Instructional Diagnosis): Tapping student perceptions of teaching. In E. C. Wadsworth (Ed.), A handbook for new practitioners, (pp. 89-93). Stillwater, OK: New Forums Press, Professional and Organizational Development Network in Higher Education.

Diamond, R. (1988). Faculty development, instructional development, and organizational development: Options and choices. In E. C. Wadsworth (Ed.), A handbook for new practitioners, (pp. 9-11). Stillwater, OK: New Forums Press, Professional and Organizational Development Network in Higher Education.

Drops, G. (1996, October). Making distance education more interactive. Paper presented at the POD Network Annual Conference, Snowbird, UT.

Education Network of Maine. (1996, November 7). Active learning in the distance classroom [Video conference].

Gaff, J. G. (1970). Toward faculty renewal: Advances in faculty, instructional, and organizational development. San Francisco: Jossey-Bass. 
Gilbert, S. W. (1996, January 23). Support service crisis: Prepare for your support service crisis. American Association of Higher Education. [On-line]. Available: aahesigt 1 list.cren.net.

Gilbert, S. W. (1995, March/April). Teaching, Learning \& Technology: The need for campus wide planning and faculty support services. Change, 27, 47-52.

Lewis, K. G. (Ed.). (1988). Face to face: A sourcebook of individual consultation techniques for faculty/instructional developers. Stillwater, OK: New Forums Press.

Moore, M. G., \& Kearsley, O. (1990). Distance education: A systems view. New York: Wadsworth.

The National University Telecommunications Network (NUTN). (1997, March 28). Teaching and learning in the computer age. Norfolk, VA: Old Dominion University, Virginia Tidewater Consortium for Higher Education [Video conference].

Povlacs (Lunde) J. (1988). The teaching analysis program and the role of the consultant. In K. G. Lewis (Ed.), Face to face: A sourcebook of individual consultation techniques for faculty/instructional developers (pp. 237-242). Stillwater, OK: New Forums Press.

Rockwell, S. K., \& King, J. W. (1995, February 9). A professor's perception to interaction in satellite education. Presented to the Association for Educational Communications and Technology, Anaheim, CA.

Rogers, S. M. (1995, December). Distance education: The options follow mission. American Association for Higher Education Bulletin, 48, 4-8.

Saltrich, S. (1994, Fall). The new instructional media: one publisher's perspective. The Department Chair, 4, 13-14.

Scott, G., \& Aden, N. (1996). NUserv distance education instructor's manual. Lincoln, NE: University of Nebraska, Division of Continuing Studies, Department of Academic Telecommunications.

Sorenson, D. L. (1994). Valuing the student voice: Student observer/consultant programs. In E. Wadsworth (Ed.), To Improve the Academy, Vol. 13, (pp. 97-108). Stillwater, OK: New Forums Press and the Professional and Organizational Development Network.

Teaching and Learning Center. (n.d.) (Teaching Analysis by Students TABS-C). Lincoln, NE: University of Nebraska-Lincoln.

University of Wisconsin Cooperative Extension. (1996, April 25). Quality distance education: lessons learned [Video conference].

Willis, B. (1992, November). Strategies for teaching at a distance. Eric Digest. Syracuse University, Syracuse, NY. (ERIC Clearinghouse on Information Resources No.ED IR 92 8).

Willis, B. (1993). Distance education: A practical guide. Englewood Cliffs, NJ: Educational Technology Publications. 


\section{Resources}

Scott, G. and Aden, N. (1996). NUserv distance education instructor's manual. Lincoln, NE: University of Nebraska, Division of Continuing Studies, Department of Academic Telecommunications. (To purchase a copy call 402-472-0400.)

Teaching and Learning Center. Teaching Analysis by Students (TABS-C). Lincoln, NE: University of Nebraska-Lincoln. (For a sample copy, call 402-472-3079.)

\section{Contact:}

Myra S. Wilhite

Teaching and Learning Center

University of Nebraska-Lincoln

115 Benton Hall

Lincoln, NE 68588-0623

(402) 472-9766

(402) 472-4932 FAX

mwilhite@unlinfo.unl.edu

Joyce Povlacs Lunde is a professor in the department of Agricultural Leadership, Education and Communication and an educational development specialist in the Office of Profession and Organizational Development at the University of NebraskaLincoln. She taught via distance for the first time in the fall, 1996, offering a class in Advanced Teaching Methods: Teaching in Postsecondary Settings to 10 students in the studio and 16 students at 7 sites across Nebraska.

Myra S. Wilhite is faculty instructional consultant at the Teaching and Learning Center and an associate professor in the department of Agricultural Leadership, Education and Communication at the University of Nebraska-Lincoln. As instructional consultant, she was invited to observe the dynamics and conduct teaching analysis in Lunde's Advanced Teaching Methods course. 


\section{Appendix A \\ University of Nebraska-Lincoln \\ Questionnaire: Using Technology for Teaching}

Name:

Date:

Major field and level of teaching/instruction:

Instructions: Indicate what and how much experience you have with contemporary learning technologies: e.g., computer-generated materials; e-mail, list-serves; Internet/World Wide Web; multi-media classroom facilities; distance delivery, including audio, video, FAX, electronic mail; data-bases and library searches; etc. Use the following:

4-Frequent use and experience

3-Moderate use and experience

1. Used computer to develop materials presentation (e.g., Persuasion, PowerPoint, Freelance).

2. Planned a course or workshop incorporating a variety of multi-media.

3. Integrated a variety of technological tools in teaching or instructional delivery.

4. Developed videotaped instructional programs.

5. Participated in a workshop or course delivered via distance.

6. Made live presentations via television.

7. Taught on-site and off-site students simultaneously.

8. Used documents camera and other distance education equipment.

9. Explored the World Wide Web.
2-Some use or experience 1-Little or no use/experience 
$\begin{array}{llll}4 & 3 & 2 & 1\end{array}$

10. Incorporated the World Wide Web in teaching.

11. Taught courses via computer.

12. Searched data bases via computer.

13. Send e-mail personally or professionally.

Please add any comments about your experiences and any concerns you have with technologies in teaching. 


\section{Appendix B}

University of Nebraska-Lincoln

ALEC 405/805: Teaching in Postsecondary Settings

Course Evaluation by Teaching Associates

In order to fill in more details in this distance education satellite course, would you give us your opinion of how the course went? Your perspectives are very important in getting the full picture. Complete and retum the questionnaire in the envelope provided. Your responses will be kept anonymous. Thank you!

A. For the following, circle the letters that best represents your view, using this key:
SA $=$ Strongly Agree
$\mathrm{D}=$ Disagree
A - Agree
$\mathrm{SD}=$ Strongly Disagree

The Course and Student Learning

1. The methods used were compatible with what the students were expected to learn.

SA A $\quad$ D $\quad$ SD

2. The technology enhanced the learning in this course.

SA A D SD

3. This course was "value-added" - -students at my sites were able to demonstrate gains or learning over time.

SA A D SD

The Teaching Associate

4. The role of the Teaching Associate was clear.

SA A D SD

5. The Teaching Associate was asked to do appropriate tasks on the site.

SA A D SD

6. The Teaching Associate could have done a lot more of the teaching.

SA A D SD

7. As a Teaching Associate, I learned a great deal about teaching and learning as I participated in this course.

SA A D SD 
8. As a Teaching Associate, I have been able to employ some of the concepts, methods, or technologies from this course in my own work. SA A D SD

9. If asked, I would do it again. SA A D SD

B. For the following, please give your feedback on the teaching and learning and your role in the class.

1. Identify something that you thought went very well in the teaching and learning at your site.

2. What might have been done differently to enhance the teaching and learning at your site?

3. Give a recommendation you have to incorporate when the course is taught again.

4. Describe something you gained personally from participating in the course. 


\section{Appendix C \\ University of Nebraska-Lincoln \\ Criteria for Self-Evaluation of Teaching Videotape}

The following criteria have been compiled to assist you in the evaluation of your teaching. Examine them prior to reviewing your tape. This should help you assess these aspects of your teaching as you watch your class being replayed.

These items are generally accepted as components of effective teaching. They have been designed so that they apply to most types of classes. However, you may find a few which are not applicable. You may also think of other criteria you want to include in your evaluation. Mark whether you are satisfied or dissatisfied with your performance for each applicable criterion. You may find it helpful to make some notes about the item(s) you find dissatisfying. These can be useful later when you consider strategies for enhancing your effectiveness.

At any time in your self-evaluation, an instructional consultant is willing to meet with you to review the particular aspects of your teaching you desire to enhance.

1. My explanations are clear.

2. I stress the important points in lectures or discussions.

3. I make good use of examples and illustrations to clarify difficult content.

4. I show enthusiasm when teaching.

5. I put material across in an interesting way.

6. I vary my voice modulation appropriately, articulate clearly, and have a good level of volume. 


\section{SATISFIED DISSATISFIED}

7. My physical movements and facial expressions effectively complement the presentation.

O

O

8. My delivery is free from annoying mannerisms.

0

9. My pace of delivery is appropriate to the topic.

10. I appear to have thorough knowledge of the subject.

11. I make effective use of media (blackboards, slides, tapes, overhead projector, etc.) which enhances my presentation.

\section{ORGANIZATION OF MATERIAL COVERED}

12. I clearly explain the objective of the lesson.

13. I state what students should know (or be able to do) following the lesson.

14. I provide a brief overview of the day's lesson to orient the students to the topic(s).

15. I address the relevance or worth of the lesson to the students.

6. I cover the right amount of information to allow the students to know or do what I expect. (I do not give too many details, or too little information.)

17. I keep the class going according to schedule.

18. I review or summarize the day's lesson. 


\section{INTERACTION WITH STUDENTS}

19. The students' interest in class appears to be aroused.

0

20. I encourage students to participate or practice skills I expect them to learn.

21. I acknowledge all questions insofar as possible.

22. I encourage constructive criticism.

Students are free to disagree.

23. I provide feedback to students regarding the correctness of their responses.

24. My interactions with students are friendly.

O

25. I am flexible when conducting a lesson.

0

26. When the class is sidetracked, I am able to bring the students back to the main topic.

27. I involve students who don't volunteer.

28. I am observant and responsive to students who have difficulty or appear disinterested.

29. The level of difficulty of the lesson appears appropriate to the level of the students in class.

UNL Teaching and Learning Center

121 Benton Hall

University of Nebraska-Lincoln

Lincoln, NE 68588-0623

Telephone: (402) 472-3079 